\title{
Farmer Seed Exchange and Crop Diversity in a Changing Agricultural Landscape in the Southern Highlands of Ethiopia
}

\author{
Leah H. Samberg • Carol Shennan • Erika Zavaleta
}

Published online: 9 March 2013

(C) Springer Science+Business Media New York 2013

\section{Introduction}

The southern highlands of Ethiopia are home to some of the planet's oldest agricultural systems, dating back 10,000 years (Brandt et al. 1997), and are considered a global center of crop diversity (Vavilov and Chester 1951). The highland landscape is made up of a patchwork of small, diverse subsistence farms, grasslands, and forests where the lines between 'human' and 'natural' are indistinct, and the actions of farmers are a driving force in the distribution of biodiversity. Crop diversity serves both to buffer the global food supply against environmental change and pest and disease outbreaks, and to maintain the sustainability of traditional small-scale agricultural systems (Gepts 2006). These diverse crops and varieties are created and maintained through seed exchange among farmers, and the scales and strengths of these pathways have enormous influence on agricultural biodiversity. In order to understand patterns of diversity, it is therefore useful to explore the patterns of farmer seed exchange that influence farmers' use of and access to agricultural biodiversity, and the ways in which cultural, demographic, and agricultural changes have the potential to enhance or erode that diversity. Our research focuses on four related questions: 1) How the scales and mechanisms of seed exchange affect diversity; 2) How those practices differ among locations, agroecological zones, and individual farms; 3) How and why those practices are changing; and 4) What the effects of those changes on diversity in this agroecosystem may be.

\section{Farmer Seed Systems in Centers of Crop Diversity}

Around the world, centers of crop diversity lie in regions where evolution of crop species has occurred through millennia of interacting natural and human selection pressures, heterogeneous habitats, isolation, migration, and farmer exchange.

L. H. Samberg $(\bowtie) \cdot$ C. Shennan $\cdot$ E. Zavaleta

University of California, Santa Cruz, Santa Cruz, CA, USA

e-mail: 1samberg@gmail.com
Farmers in these regions select crops for a range of attributes, including yield in low-fertility conditions, resistance to pests and disease, interannual stability of production, and a suite of dietary, cultural, and economic needs (Zeven 1998). The frequency of seed turnover and sources of seed heavily influence the diversity accessible to farmers (Pressoir and Berthaud 2004). Molecular analyses have in many cases shown tight links between patterns of seed exchange and the distribution of genetic diversity (e.g., vom Brocke et al. 2003; Hadado et al. 2010). Genetic diversity of crop varieties has the potential to increase productivity, regulate nutrient cycling and microclimatic conditions, reduce temporal variability, and maintain resistance and resilience in the face of socioeconomic or environmental change (Altieri 1999; Shennan 2008). Securing appropriate seed is crucial for small-scale farmers (Almekinders et al. 1994). Farmers in traditional agricultural systems acquire seed from four primary sources: their own saved seed, gifts or exchanges with other farmers, purchase in local markets, or through government agricultural extension services.

In Ethiopia, as much as $90 \%$ of seed planted each year is drawn from farmers' own saved seed (Kebebew et al. 2001; Lipper et al. 2005). Benefits from the use of saved seed include adaptation to local conditions, known seed quality, and reduced monetary and social costs (Badstue et al. 2007). However, maintenance of diversity requires seed exchange, as does unexpected seed loss and the desire to experiment with new crops or cultivate new fields (Dennis et al. 2007). While seed exchange generally takes place within communities, long distance exchanges may be more common than previously thought, and traditional agricultural systems are not isolated with respect to the flow of genetic material (Perales et al. 2003). Non-monetary seed exchanges among farmers, either within or between communities, are often mediated by social institutions (Dennis et al. 2007).

Another source of seed is via local markets where farmers who are both producers and consumers sell surplus produce, grain, and seed to other farmers. Market acquisition of seeds has traditionally been seen as an action of last resort for seed- 
insecure farmers. However, recent research has shown that local markets in fact play a key role in farmer seed sourcing (Sperling and McGuire 2010).

The final source of seed in traditional systems is the network of government research, production, and extension that make up the formal seed system. In Ethiopia, the formal seed system continues to play only a small role in seed acquisition habits of small subsistence farmers, and in 2002 improved seed made up less than $3 \%$ of the total cultivated area in the country (Belay and Degnet 2004).

While conventional wisdom suggests that land-use intensification, increased market integration, and cultural or environmental change are associated with the loss of crop genetic diversity (e.g., Bellon 1996; Teklu and Hammer 2006) in many cases traditional and modern varieties co-exist (Brush and Meng 1998), and may even enrich diversity (Vadez et al. 2004).

\section{Study Site}

The Gamo highlands, among the world's oldest agricultural landscapes, rise from the Ethiopian Rift Valley to elevations over $4,000 \mathrm{~m}$ in a chain roughly $100 \mathrm{~km}$ long and $30 \mathrm{~km}$ wide $\left(06^{\circ} 02-27^{\prime} \mathrm{N}, 37^{\circ} 10-37^{\prime} \mathrm{E}\right)$. Native vegetation includes mixed deciduous woodlands, dry evergreen montane forest, and alpine grasslands. Annual rainfall is bimodal, and mean annual temperatures range from $10{ }^{\circ} \mathrm{C}$ to $25^{\circ} \mathrm{C}$ (FDRE 2000). The remote and rugged terrain has precluded widespread industrialization or modernization; two vehicleaccessible dirt roads cross the southern and northern reaches, while the central areas have little to no road access. The population is close to one million people (FDRE 2008).

The Gamo is dominated by small-scale subsistence agriculture, made up of farms of less than one hectare. Nationally, $95 \%$ of agricultural output comes from subsistence farms, and $69 \%$ of households farm on one hectare or less (CSA 2003). Agriculture in the Gamo highlands is based on a diverse combination of annual and perennial crops, agroforestry, and livestock management. Enset (Ensete ventricosum), a clonally-propagated perennial tree crop in the Musaceae, or banana family, serves as a staple starch, and enset plantations along with root, vegetable, and tree crops are clustered around a central homestead. Crop fields are beyond this ring, and sometimes spread over a large area. Barley is the most important cereal crop in the region, especially at high elevations, along with wheat, and maize and sorghum at lower elevations (Samberg et al. 2010).

The Gamo highlands are spread across five districts, each of which is home to a market and government extension office, all within the Gamo-Gofa Zone, within the Southern Nations, Nationalities, and Peoples Region (SNNPR) of Ethiopia. Agricultural communities generally comprise 500-800 household farms.

\section{Methods}

Selection of Communities

In order to investigate the effects of farmer seed networks on crop diversity in the Gamo highlands, household interviews were carried out in 12 communities in the region over 6 months during the main growing season in 2008-2009. Drawing from prior research in the region (Samberg et al. 2010), we stratified our sample communities based on characteristics of elevation and location. First, we drew four sites from from each of three elevation zones, defined as 'low' $(<2,400 \mathrm{~m})$, 'mid-elevation' $(2,400-2,800 \mathrm{~m})$ and 'high' $(>2,800 \mathrm{~m})$. Second, we split these evenly between the two northern and three southern districts in the range. Given logistical and political constraints to randomization, we met with district administrators in each of the five districts to select sample communities that met these requirements. The resulting list of 12 sample communities represents four low, four mid-elevation, and four high-elevation communities, two each in the northern and southern portions of the Gamo (Table 1; Fig. 1). All communities share Gamo ethnicity, tribal affiliation, and language, and are of comparable size.

\section{Selection of Farms}

In each community, households were selected for interviews and on-farm surveys through discussion with the community chairman and community elders. The lack of a formal listing of community residents precluded randomization. Therefore households were stratified by socioeconomic status, as described by the chairman and elders, identified as

Table 1 Sample communities in the Gamo Highlands, Ethiopia. Identified by location in the northern or southern portion of the study area, elevation class (Low: 1,800-2,350 m above sea level, Mid: 2,400 2,800 m, High: $2,800-3,100 \mathrm{~m}$ ), and mean altitude of farms in the community. Site number corresponds to the map presented in Fig. 1

\begin{tabular}{lllll}
\hline Site & Community & $\begin{array}{l}\text { North/ } \\
\text { South }\end{array}$ & $\begin{array}{l}\text { Elevation } \\
\text { class }\end{array}$ & $\begin{array}{l}\text { Mean altitude } \\
(\mathrm{m})\end{array}$ \\
\hline 1 & Hanika & $\mathrm{S}$ & Low & 1,849 \\
2 & Weyza & $\mathrm{N}$ & Low & 2,184 \\
3 & Kogo & $\mathrm{N}$ & Low & 2,207 \\
4 & Bula & $\mathrm{S}$ & Low & 2,339 \\
5 & Choye & $\mathrm{S}$ & Mid & 2,565 \\
6 & Boko & $\mathrm{S}$ & Mid & 2,628 \\
7 & Lisha & $\mathrm{N}$ & Mid & 2,666 \\
8 & Sete & $\mathrm{N}$ & Mid & 2,734 \\
9 & Zute & $\mathrm{N}$ & High & 2,844 \\
10 & Gena Kare & $\mathrm{N}$ & High & 2,939 \\
11 & Gughe & $\mathrm{S}$ & High & 2,987 \\
12 & Chosha & $\mathrm{S}$ & High & 3,012 \\
\hline
\end{tabular}




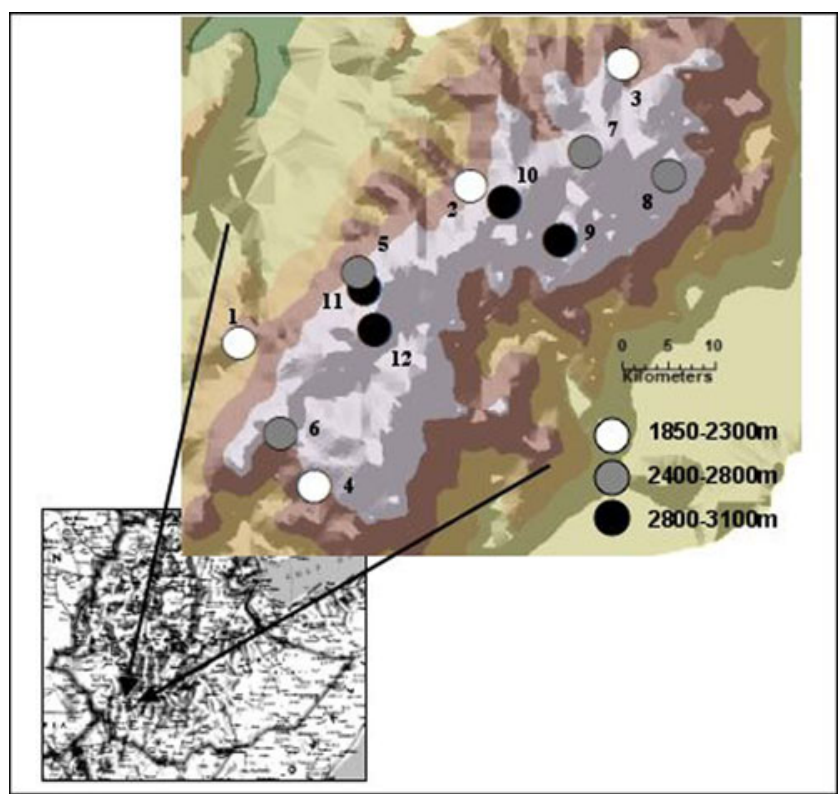

Fig. 1 Map of sample communities in the Gamo Highlands, southern Ethiopia. Inset shows location in southwest Ethiopia $\left(06^{\circ} 02-27^{\prime} \mathrm{N}, 37^{\circ}\right.$ $\left.10-37^{\prime} \mathrm{E}\right)$. The 12 sample communities are numbered in order of increasing elevation, and labeled according to Table 1. Coloration represents elevation class (Low, Mid, and High)

'large,' 'medium,' and 'small' farms. Rankings are designed to capture overall resource level and generally correspond to farm size; however the non-contiguous nature of farms in the region made specific measurements of farm size impractical. This methodology has possible shortcomings; perceptions of socioeconomic status may differ between communities, and rankings of a given household may be skewed by several factors, such as a household head's status in the community. However, observations by the field team, including members local to the region, indicated that neither of these was evident to a problematic degree. Three to four households were sampled opportunistically from each of these wealth rankings, for a total of ten households in each community.

\section{Household Interviews}

A total of 121 household interviews were administered to the head of each household by the principal investigator and primary research assistant, who was native to the region, as well as other short-term research assistants. Interviews were conducted in the local language and dialect, and the survey instrument was pre-tested on farmers in a non-sample community prior to the start of the study.

Interviews were divided into three sections:

1. A farm inventory of all crops and varieties present, including a farm walk and visual assessment, and quantification of livestock ownership.
2. A structured questionnaire on seed acquisition and exchange comprising a series of questions discussing sources of planting material, frequency of acquisition, and mechanisms of exchange for each crop. Most questions were presented in a multiple-choice format, and responses were assessed through several related questions in order to evaluate consistency, including the initial source of seed for each crop grown, the approximate time since acquisition, the reason for acquisition, and the rationale for selecting the source. These responses were coded for statistical analysis.

3. A semi-structured questionnaire with open-ended questions addressing changes to seed exchange practices, crop diversity, livestock management, and other changes in agriculture in the region as perceived by farmers.

\section{Data Analysis}

Responses to the structured survey were compared across elevation class, north/south location, and farm resource level. Mean values were compared using a full-factorial ANOVA approach, and proportional responses were compared using Pearson's chi-squared tests. Statistical analysis was performed in JMP software.

The similarity of barley and enset varieties cultivated at the community scale was assessed for each pair of communities using a Bray-Curtis similarity index in the EstimateS software package. Similarity matrices created for barley and enset varieties were correlated with the distance and elevation difference between each pair of communities using a Mantel test in XLSTAT.

\section{Key Informant Interviews}

Unstructured key informant interviews were conducted in English with the chief agricultural extension officer in four of the five districts included in this study, as well as with the rural development officer at the larger zonal level. These interviews were designed to gather a broad understanding of the policy context, and were not analyzed in a quantitative manner.

\section{Results}

\section{Crop Diversity}

The farm survey identified 34 food crop species across the study area, excluding spices and oil crops, and farms cultivated 11 food crop species on average. Several of these crops were represented by numerous farmer-identified varieties. Farmers identified a total of 33 named barley varieties 
and 77 enset varieties, with an average of 2.3 barley varieties and eight enset varieties per farm. ${ }^{1}$ The identity and diversity of crop species on farms is strongly related to elevation and agroecological conditions and is also affected by location and farm size.

\section{Elevation}

The range's steep elevation gradient is a primary factor in all aspects of production in the Gamo, creating different growing conditions in communities only short distances apart (CSA 2003; Tesfaye 2008). In addition, farmers described the highlands above $2,400 \mathrm{~m}$ as traditionally more extensively cultivated. Crop diversity decreases significantly with increasing elevation $(p<0.0001)$ across the range from fewer than eight species per farm at the highest elevations to more than 16 at the lowest (Table 2). Conversely, the diversity of barley varieties per farm is significantly lower at low elevations, with 1.4 varieties per farm on average ( $p<0.0001$; Table 2$)$. Barley is a more important part of the cropping system and diet at high elevations, as fewer crop species are productive on these farms.

\section{Location}

Farms in the northern half of the range have, on average, a significantly greater number of enset varieties than those in the south, 9.53 vs. 6.63 , independent of elevation or farm size $(p<0.001$; Table 2$)$.

\section{Farm Resource Level}

Across all elevations and locations, small farms cultivate fewer crop species than medium or large farms, with an average of 9.14 crops per farm $(p<0.05)$ and fewer barley varieties, with an average of 1.6 varieties $(p<0.0001$; Table 2$)$.

\section{Seed Exchange Mechanisms}

The majority of farmers surveyed get most of their seed from their own previous year's harvest. Of the 302 barley fields analyzed, $55 \%$ were planted with the farmer's seed from the previous year (Table 4), and $70 \%$ of farmers had not acquired enset clones from an outside source in the past 3 years. However, every farmer surveyed was an active participant in seed exchange and acquisition: $45 \%$ reported acquiring new seed for cereal crops in the past 3 years, and $62 \%$ reported acquiring seed for root and vegetable crops in that time. Of farmers' most recent seed acquisitions, a greater proportion was acquired to experiment with new crops and varieties $(58 \%)$ than to replace inadequate or failed seed (42\%).

\footnotetext{
$\overline{{ }^{1} \text { See Samberg }}$ et al. (2010) for more detailed information on crop diversity in this system.
}

\section{Markets}

Local markets are the most common source of seed acquisition, making up $46 \%$ of recent acquisitions, and $46 \%$ of farmers identified markets as the most important seed source (Table 3). On average, farmers in the Gamo attend four different markets each week, often traveling to communities of different elevation and agroecological regime. A quarter of barley fields were planted with seed purchased in local markets (Table 4).

\section{Government Extension}

The second most common source of seed is the formal government agricultural extension service; $43 \%$ of respondents indicated that their most recent seed acquisition was from government extension (Table 3). Seed from extension offices is present throughout the Gamo, most commonly maize, wheat, peas, beans, root crops, and garden vegetables. Thirty-four percent of farmers reported receiving seed from government extension in the previous year, and $43 \%$ reported having at some point received cereal seed from extension offices (Table 3).

The formal seed sector is accessed as a source of seed largely for more recently introduced crops; only four farmers reported planting barley from government extension. Though there is one extension-run enset nursery, none of the surveyed farmers had planted enset from government channels.

\section{Neighbors as a Seed Source}

Though $33 \%$ of farmers claimed that neighbors were the best source of seed, citing local adaptation, accessibility, and good information, only $11 \%$ of recent acquisitions came directly from neighbors (Table 3) as a result of what they described as their reluctance to 'beg' for seed. They also noted that their neighbors are often unable or unwilling to donate more than a very small quantity of seed. For enset cultivation, however, exchange with family and neighbors is the primary source of new material, and was the source for nearly all of the farmers reporting planting new enset in the past 3 years. Discussion of enset sourcing elicited the strongest positive attitude toward social networks of farmer exchange. This is borne out by the fact that $63 \%$ of farmers say they have given or sold enset clones to other farmers.

\section{Geographic Patterns of Seed Exchange}

Based on a Bray-Curtis similarity index, distance between communities is closely correlated with similarity of enset varieties $(p<0.0001)$, and, to a lesser extent, with barley varieties $(p<0.01)$. This pattern indicates a patchwork of diversity at a scale larger than the individual community. 
Table 2 Farmers' responses regarding crop diversity in the Gamo Highlands, Ethiopia. Drawn from 121 household surveys in 12 communities. Responses are compared between farmers in different elevation classes, in the northern and southern portions of the study area, and between farmers identified as having large, medium, or small farms. Values represent average per farm

\begin{tabular}{|c|c|c|c|c|c|c|c|c|c|}
\hline Average per farm & $\begin{array}{l}\text { Total } \\
N=121\end{array}$ & $\begin{array}{l}\text { High } \\
N=44\end{array}$ & $\begin{array}{l}\text { Mid } \\
N=38\end{array}$ & $\begin{array}{l}\text { Low } \\
N=39\end{array}$ & $\begin{array}{l}\text { North } \\
N=60\end{array}$ & $\begin{array}{l}\text { South } \\
N=61\end{array}$ & $\begin{array}{l}\text { Large } \\
N=37\end{array}$ & $\begin{array}{l}\text { Medium } \\
N=35\end{array}$ & $\begin{array}{l}\text { Small } \\
N=42\end{array}$ \\
\hline \# of crops & 11.4 & $7.52 *$ & 10.71 & $16.59 *$ & 11.22 & 11.67 & 12.23 & 11.53 & $9.14 *$ \\
\hline \# of barley varieties & 2.27 & 2.77 & 2.55 & $1.43^{*}$ & 2.28 & 2.26 & 2.94 & 2.56 & $1.63 *$ \\
\hline \# of enset varieties & 8.09 & 7.57 & 8.21 & 8.58 & $6.63^{*}$ & 9.53 & 8.53 & 9.06 & 7.43 \\
\hline
\end{tabular}

*Significantly different from overall mean value based on full-factorial ANOVA $(\alpha=0.05)$

Inter-community exchange causes cropping decisions made by farmers in one community to affect the diversity available to farmers in neighboring communities.

Communities also share crop varieties in common with communities of a similar elevation, implying that seed exchange is less likely to occur across large elevation gradients. Barley stands out as an especially elevationdependent crop, as the similarity of varieties between communities is strongly correlated with similarity in elevation $(p<0.0001)$.

\section{Differing Seed Exchange Practices}

Differences in seed security, access to extension, and ability to experiment with new crops create a gradient of seed exchange practices across the region.

Table 3 Farmer responses regarding seed exchange practices in the Gamo Highlands, Ethiopia. Drawn from 121 household surveys in 12 communities. Responses are compared between farmers in different

\section{Elevation}

Farmer seed sourcing systems can vary by elevation (e.g., McGuire 2008), and this is seen clearly in the Gamo. In addition to growing fewer barley varieties, farmers at low elevations are less seed secure for barley; only $39 \%$ of barley fields at low elevations were planted with the farmer's own saved seed, significantly lower than the $61 \%$ and $58 \%$ at high and mid elevations $(p<0.05$; Table 4$)$.

The second major effect of elevation on seed sourcing systems in the region (and in others; e.g., Tunstall et al. 2001 ) is that government agricultural extension plays less of a role at high elevations. Overall, $27 \%$ of farmers at high elevations have received cereal seed from extension, lower than the $50 \%$ and $54 \%$ at mid- and low elevations $(p<0.05$; Table 3). Many of the crops provided by extension offices

elevation classes, in the northern and southern portions of the study area, and between farmers identified as having large, medium, or small farms. Values represent percent of respondents within those groupings

\begin{tabular}{|c|c|c|c|c|c|c|c|c|c|}
\hline$\%$ of respondents & $\begin{array}{l}\text { Total } \\
N=121\end{array}$ & $\begin{array}{l}\text { High } \\
N=44\end{array}$ & $\begin{array}{l}\text { Mid } \\
N=38\end{array}$ & $\begin{array}{l}\text { Low } \\
N=39\end{array}$ & $\begin{array}{l}\text { North } \\
N=60\end{array}$ & $\begin{array}{l}\text { South } \\
N=61\end{array}$ & $\begin{array}{l}\text { Large } \\
N=37\end{array}$ & $\begin{array}{l}\text { Medium } \\
N=35\end{array}$ & $\begin{array}{l}\text { Small } \\
N=42\end{array}$ \\
\hline \multicolumn{10}{|l|}{ Most recent seed acquisition } \\
\hline From markets & 46 & 53 & 35 & 50 & $56^{*}$ & $35^{*}$ & 30 & 31 & $67 *$ \\
\hline From extension & 43 & 29 & 59 & 42 & $33 *$ & $54 *$ & $63^{*}$ & 54 & $28^{*}$ \\
\hline From neighbors & 11 & 18 & 6 & 8 & 12 & 11 & 7 & 15 & 12 \\
\hline Due to loss/out of necessity & 42 & 44 & 41 & 41 & $53 *$ & $30 *$ & 35 & $17^{*}$ & $63^{*}$ \\
\hline \multicolumn{10}{|l|}{ Preferred seed source } \\
\hline Market & 44 & 55 & 42 & 38 & 45 & 46 & 52 & 33 & 45 \\
\hline Government & 20 & 13 & 24 & 26 & 13 & 25 & 29 & 33 & $5^{*}$ \\
\hline Neighbors & 33 & 33 & 30 & 34 & 42 & 24 & $19 *$ & 31 & $48^{*}$ \\
\hline \multicolumn{10}{|l|}{ Extension services } \\
\hline Received cereal seed & 43 & $27 *$ & 50 & 54 & $33^{*}$ & $52 *$ & 43 & $63 *$ & $26^{*}$ \\
\hline Received seed/cutting; fruit, veg, root crop & 31 & 34 & 32 & 28 & 38 & 25 & 46 & 37 & $14^{*}$ \\
\hline Seed in the past year & 34 & 27 & 34 & 41 & 27 & 41 & 43 & 54 & $12^{*}$ \\
\hline \multicolumn{10}{|l|}{ Barley seed security } \\
\hline Acquire barley seed every year & 18 & 16 & 14 & 25 & 19 & 17 & 6 & 3 & $44^{*}$ \\
\hline Most recent acquisition due to loss/necessity & 74 & 64 & 69 & 85 & 72 & 75 & $38 *$ & 67 & $100^{*}$ \\
\hline
\end{tabular}

*Significantly different from overall percentage based on Pearson's chi-squared tests for proportions $(\alpha=0.05)$ 
Table 4 Seed sources for 302 barley fields found on 121 surveyed farms in the Gamo Highlands, Ethiopia. Sources compared between fields in high, mid, and low elevation classes, in the northern and southern portions of the study area, and between farms identified as large, medium, or small. Values represent percent of fields within those groupings

\begin{tabular}{|c|c|c|c|c|c|c|c|c|c|}
\hline$\%$ Barley fields planted with & $\begin{array}{l}\text { Total } \\
N=302\end{array}$ & $\begin{array}{l}\text { High } \\
N=137\end{array}$ & $\begin{array}{l}\text { Mid } \\
N=101\end{array}$ & $\begin{array}{l}\text { Low } \\
N=64\end{array}$ & $\begin{array}{l}\text { North } \\
N=142\end{array}$ & $\begin{array}{l}\text { South } \\
N=160\end{array}$ & $\begin{array}{l}\text { Large } \\
N=111\end{array}$ & $\begin{array}{l}\text { Medium } \\
N=93\end{array}$ & $\begin{array}{l}\text { Small } \\
N=72\end{array}$ \\
\hline Farmer's own seed & 55 & 58 & 61 & $39^{*}$ & $62^{*}$ & $49^{*}$ & 64 & 51 & 49 \\
\hline Seed from market & 25 & 21 & 24 & $38^{*}$ & $20^{*}$ & $31^{*}$ & $14^{*}$ & 23 & $43^{*}$ \\
\hline Seed from neighbors & 16 & 14 & 14 & 25 & 13 & 19 & 17 & 20 & 8 \\
\hline
\end{tabular}

*Significantly different from overall percentage based on Pearson's chi-squared tests for proportions $(\alpha=0.05)$

are lowland crops, while the highland areas are not suitable for many improved crops. Similar research on sorghum in Ethiopia found that farmers in the highlands were less positive about formal seed provision than those in lowland areas (McGuire 2005).

\section{Location}

Though ethnically homogeneous, topographically contiguous, and of similar elevation, the northern and southern halves of the Gamo highlands showed markedly different patterns of seed exchange. Farmers in the south tend to be more active participants in seed exchange institutions. The average farmer in the south attends more markets each week than those in the north (4.66 vs. $3.38 ; p<0.0001)$ and new seed acquisitions are less likely to be due to necessity ( $30 \%$ vs. $53 \%$ of recent acquisitions, $p<0.05$; Table 3 ).

Farmers in the south are also more likely to have received cereal seed from extension (52 \% vs. $33 \%$ $p<0.05$; Table 3 ). We observed variability in the extent to which agricultural extension offices are staffed, funded, and engaged with farmers. Offices in southern district tended to be staffed with younger agents who appeared more interested in active outreach, which may have implications for seed sourcing preferences across the region. In addition, the southern half of the range is more directly connected to lowland markets in neighboring regions, and this historical contact with foreign products may have led to greater comfort with experimentation and adoption of new planting material.

\section{Farm Resource Level}

Within communities, there is variation in seed sourcing strategies at the farm scale. Poorer or smaller farms are far less likely to get seed from extension or to have a favorable opinion of extension seed. Only $12 \%$ of respondents from small farms reported getting seed from extension in the past year, significantly less than the $56 \%$ from medium-sized farms and $44 \%$ on large farms $(p<0.0001$; Table 3$)$. Relatedly, only $5 \%$ of respondents from small farms listed extension as the most important seed source, compared to $31 \%$ and $28 \%$ on medium and large farms $(p<0.01$; Table 3 ). These results are consistent with previous findings on seed sourcing in Ethiopia, which indicate that extension agents provide a greater range of products and services to wealthier farmers (Belay and Degnet 2004).

Small farms are far less likely to be seed secure, with $44 \%$ reporting planting barley from off-farm sources every year, significantly more than the $6 \%$ and $3 \%$ among medium and large farms $(p<0.0001$; Table 3$)$. They are significantly more likely than medium or large farms to acquire both barley seed $(p<0.0001)$ and seed of all kinds $(p<0.01$; Table 3$)$ out of necessity rather than for experimentation, and barley fields on small farms are more likely than those on other farms to be planted with seed from markets $(p<0.0001$; Table 4$)$.

\section{Discussion}

Farmers' ability to cultivate diverse crops and varieties depends largely on elevation and agroecological zone. Farmers' decisions about diversity and seed acquisition, their perceptions of change in the landscape, and the extent to which they adapt or maintain the diversity of their agricultural systems differ in significant ways among farms at different elevations, farms in the northern and southern portions of the study area, and farms of different size. Together, these responses provide a perspective of changing seed exchange in this landscape, and the potential consequences of those changes for agricultural biodiversity.

\section{Increases in Human Population Density}

The population of Ethiopia's Southern Nations, Nationalities, and Peoples Region grew at a rate of $2.9 \%$ \%/year between 1994 and 2007 , with $48 \%$ of the current population under the age of 15 (FDRE 2008). Population growth in the Gamo highlands appears to be substantially higher than this, although changes in census methodology prevent an accurate calculation. 
Political barriers to land sale and lack of off-farm employment opportunities have led to a rapid decrease in farm size from 2 ha to less than 0.5 ha per household.

In all 12 surveyed communities, farmers identified population growth as the most pressing threat to the agricultural system in the Gamo highlands. Farmers report diverse effects of increasingly limited availability of land, including shortened fallow periods, detrimental effects on crop productivity and soil health, reduced availability of grazing land, and abandonment of crops. Of the farmers surveyed, $40 \%$ reported decreasing their livestock holdings due to shortage of pasture, $46 \%$ reported decreases in crop productivity due to continuous cultivation of fields and lack of manure for fertilizer, and $20 \%$ reported abandoning specific crops entirely due to land or manure shortage.

\section{Replacement of Traditional Crops}

While many farmers in the Gamo maintain that little change is occurring to their way of life, changes are occurring in the decision-making processes that determine crop diversity. In the highlands, the most noticeable change is the ongoing replacement of barley with improved wheat or Triticale, a wheat-rye hybrid. These varieties were introduced through extension, NGOs, and missionary organizations, and are now exchanged in local markets. A number of farmers report the replacement of at least some barley with wheat over the past several years due to its higher productivity and market value, though only a few claim to have entirely abandoned barley varieties.

For the time being, there appears to be little danger of the replacement of traditional barley varieties with improved barley, as national research stations have yet to produce adequate barley seed for smallholder farmers (Bishaw et al. 2008). In 2005, only $16 \%$ of the national demand for barley seed was met by government extension (Alemu and Spielman 2006), and on-farm trials have shown that farmer varieties outperformed improved varieties under all but the highest-input conditions (Abay and Bjornstad 2009).

\section{Cultural and Political Pressures}

Farmer and key informant interviews also identified changing cultural and political factors affecting social networks, and thus possibly affecting seed exchange and crop diversity. Recent government interventions in the region have been in the form of work-for-food programs, through which farmers work on government-mandated soil and water conservation or construction projects in return for grain and input packages. The conservation measures implemented are often not locally appropriate, and enforced participation can lead to the breakdown of traditional communal labor institutions, as farmers need all remaining time for their own farms. In addition, a recent survey has shown that such programs have not had significant effects on food security in Ethiopia (Gilligan et al. 2008).

In addition, farmers identified both Protestant and Ethiopian Orthodox churches as applying strong pressures to change traditional institutional structures, including pasture and forest management systems, labor-sharing institutions, and cultural practices that place value on traditional crops. Church affiliation provides access to new networks of seed provision, labor, and food aid, and many farmers report planting seed received from their church and abandoning communal institutions for church institutions. These weakening social ties can increase transaction costs for the necessary information and knowledge that accompanies crop diversity.

\section{Effects of Changing Seed Exchange Practices on Crop Diversity}

Changes in farmer seed sourcing systems due to increased use of markets, dismantling of traditional social institutions, or the ability of farmers to save seed can all affect crop diversity. Conventional wisdom suggests that these changes are associated with the loss of crop genetic diversity, a decrease in the number of farmers growing landraces, and the area of landrace cultivation on farms (Bellon 1996; Teklu and Hammer 2006). However, an overarching trend seen in these data is that greater interaction with seed supply institutions and greater participation in seed exchange activities is correlated with higher levels of on-farm diversity at both variety and species scales. For example, attending a greater number of markets each week is correlated with cultivating a greater number of barley varieties, and farmers who list government extension as the most important seed source have higher levels of overall crop diversity than those who do not $(p<0.05)$.

\section{Conclusion}

The patterns of seed exchange and crop diversity seen across Gamo farms indicate that increases in market access and extension presence can have positive effects on crop diversity, at least in the short term. However, the pressure of human population growth in this system threatens on-farm diversity, as farms become smaller and farmers are forced to abandon crops and varieties. In this situation, farmers are increasingly likely to choose high productivity crops, such as improved wheat, over their preferred traditional crops. Weakening social ties within communities due to the fracturing effects of religious conflict and cultural change may increase the dependence of farmers on outside sources for seed.

In light of these changes, there are reasons to believe that, in the long term, the trend of increasing diversity with 
market and extension access will reverse itself. First, studies in similar systems have identified a time lag between adoption of new crops and varieties, and abandonment of old ones (Brush 1992). As farms become smaller, this eventual crop abandonment appears increasingly likely. Second, the most prevalent early adopters of new technologies, in this and other systems, are farmers with greater access to land and resources. These farmers are able to add new crops and varieties while maintaining traditional ones, while smaller farmers who adopt new crops will by necessity replace other crops on the limited land they have available. Third, even if varieties are not abandoned, greater seed turnover and smaller plots of traditional varieties increase the potential for erosion of genetic diversity, leaving crop populations (and thus farmers) increasingly vulnerable to variable conditions (Tunstall et al. 2001).

Seed sourcing and exchange decisions made by farmers in the Gamo highlands create a safety net protecting against the loss of crop diversity, allow for adaptation to specific agroecological conditions, and create avenues for resilience in the face of change. Farms in the region currently display a spectrum of attitudes and practices that shape their seed systems, with more conservative approaches in the north and at higher elevations, while in the south and at lower elevations there is a greater embrace of new seeds and seed sources. Within these communities, better-off farmers have greater access to the formal seed supply, and the ability to augment, rather than replace, crops and varieties. It is likely that this trend toward greater integration of new planting material and dependence on outside sources represents the direction of change in the Gamo region in the years to come.

Local seed systems are efficient, however they are not designed to adapt to rapid change (Almekinders et al. 1994). Since it appears that increased exchange of seed and information among farmers has the potential to increase on-farm diversity, successful conservation efforts are likely to be those that bolster farmer seed networks and access to genetic material, while maintaining the value of diversity among farmers.

Creating stronger linkages between the formal seed system and farmer exchange networks will allow new genetic material to be vetted by farmers and disseminated appropriately (AwHassan et al. 2008; de Boef et al. 2010). Facilitating efficient exchange of seed and information may allow farmers to maintain higher levels of on-farm diversity (Stromberg et al. 2010). Potential interventions include establishing local seed banks, holding seed fairs and other venues for farmer exchange of seed and information, supporting key farmers or communities that maintain a higher degree of diversity, and documenting farmer knowledge of variety attributes, use, and management (de Boef 2008; Sthapit et al. 2008). Finally, local ecological and cultural knowledge and traditional beliefs can dovetail closely with agricultural practices (Bishaw et al. 2008), and supporting these practices through local cultural organizations and expositions can also strengthen seed exchange networks and act as a mechanism for the conservation of crop diversity in the face of shrinking farms and changing conditions.

\section{References}

Abay, F., and Bjornstad, A. (2009). Specific Adaptation of Barley Varieties in Different Locations in Ethiopia. Euphytica 167(2): 181-195.

Alemu, D., and Spielman, D. (2006). Ethiopian Seed Systems: Regulations, Institutions, and Stakeholders, ESSP Policy Conference Brief No. 11.

Almekinders, C., Louwaars, N. P., et al. (1994). Local Seed Systems and Their Importance for an Improved Seed Supply in Developing Countries. Euphytica 78: 207-216.

Altieri, M. A. (1999). The Ecological Role of Biodiversity in Agroecosystems. Agriculture, Ecosystems \& Environment 74(1-3): 19-31.

Aw-Hassan, A., Mazid, A., et al. (2008). The Role of Informal Farmerto-Farmer Seed Distribution in Diffusion of New Barley Varieties in Syria. Experimental Agriculture 44: 413-431.

Badstue, L. B., Bellon, M. R., et al. (2007). The Dynamics of Farmers' Maize Seed Supply Practices in the Central Valleys of Oaxaca, Mexico. World Development 35(9): 1579-1593.

Belay, K., and Degnet, A. (2004). Challenges Facing Agricultural Extension Agents: A Case Study from South-Western Ethiopia. African Development Bank.

Bellon, M. R. (1996). Dynamics of Crop Infraspecific Diversity: A Conceptual Framework at the Farmer Level. Economic Botany 50(1): 26-39.

Bishaw, Z., Sahlu, Y., et al. (2008). The Status of the Ethiopian Seed Industry. Farmers, Seeds and Varieties: Supporting Informal Seed Supply in Ethiopia. M. Thijssen, Wageningen International.

Brandt, A. S., Spring, A., et al. (1997). The "Tree Against Hunger." Enset-Based Agricultural Systems in Ethiopia. American Association for the Advancement of Science, New York.

Brush, S. B. (1992). Reconsidering the Green Revolution: Diversity and Stability in Cradle Areas of Crop Domestication. Human Ecology 20(2).

Brush, S. B., and Meng, E. (1998). Farmers' Valuation and Conservation of Crop Genetic Resources. Genetic Resources and Crop Evolution 45: 139-150.

CSA. (2003). Ethiopian Agricultural Sample Enumeration 2001/2002 (1994 E.C.) Report on Socio-economic Characteristics of the Populations in Agriculture Households, Land Use, and Area and Production of Crops, Part 1. Central Statistics Authority. Addis Ababa.

De Boef, W. S. (2008). Agrobiodiversity, Conservation Strategies, and Informal Seed Supply. Farmers, Seeds, and Varieties: Supporting Informal Seed Supply in Ethiopia. M. Thijssen, Z. Bishaw, A. Beshir and W. S. De Boef, Wageningen International.

De Boef, W. S., Dempewolf, H., et al. (2010). Integrating Genetic Resource Conservation and Sustainable Development into Strategies to Increase the Robustness of Seed Systems. Journal of Sustainable Agriculture 34(5): 504-531.

Dennis, E., Ilyasov, J., et al. (2007). Local Institutions and Plant Genetic Resources in Rural Uzbekistan and Some Theoretical Implications. World Development 35(9): 1564-1578.

FDRE (2000). Agroecological Zonation of Ethiopia. Federal Democratic Republic of Ethiopia. Ministry of Agriculture, Addis Ababa. 
FDRE (2008). Summary and Statistical Report of the 2007 Population and Housing Census. Federal Democratic Republic of Ethiopia. Population Census Commission, Addis Ababa.

Gepts, P. (2006). Plant Genetic Resources Conservation and Utilization: The Accomplishments and Future of a Societal Insurance Policy. Crop Science 46(5): 2278-2292.

Gilligan, D., Hoddinott, J., et al. (2008). An Analysis of Ethiopia's Productive Safety Net Program and Its Linkages. International Food Policy Research Institute, Washington DC.

Hadado, T. T., Rau, D., et al. (2010). Adaptation and Diversity Along an Altitudinal Gradient in Ethiopian Barley (Hordeum Vulagre) Landraces Revealed by Molecular Analysis. BMC Plant Biology 10: 121.

Kebebew, F., Tsehaye, Y., et al. (2001). Morphological and Farmers Cognitive Diversity of Barley (Hordeum Vulgare) at Bale and North Shewa of Ethiopia. Genetic Resources and Crop Evolution 00: $1-10$

Lipper, L., Cavatassi, R., Winters, P. (2005). Seed Systems, Household Welfare and Crop Genetic Diversity: An Economic Methodology Applied in Ethiopia. UN FAO Agricultural and Development Economics Division. ESA Technical Paper, November 2005.

McGuire, S. (2005). Getting Genes: Rethinking Seed System Analysis and Reform for Sorghum in Ethiopia. PhD dissertation, Wageningen University, Netherlands.

McGuire, S. J. (2008). Securing Access to Seed: Social Relations and Sorghum Seed Exchange in Eastern Ethiopia. Human Ecology 36: 217-229.

Perales, H. R., Brush, S. B., et al. (2003). Dynamic Management of Maize Landraces in Central Mexico. Economic Botany 57: 21-34.

Pressoir, G., and Berthaud, J. (2004). Patterns of Population Structure in Maize Landraces from the Central Valleys of Oaxaca in Mexico. Heredity 92: 88-94.

Samberg, L. H., Shennan, C., et al. (2010). Human and Environmental Factors Affect Patterns of Crop Diversity in an Ethiopian Highland Agroecosystem. The Professional Geographer 62(3): 395-408.
Shennan, C. (2008). Biotic Interactions, Ecological Knowledge, and Agriculture. Philisophical Transactions of the Royal Society B 363: 717-739.

Sperling, L., and McGuire, S. (2010). Understanding and Strengthening Informal Seed Markets. Experimental Agriculture 46(2): 119-136.

Sthapit, B., Subedi, A., et al. (2008). Practices supporitng community management of farmers' varieties. In Thijssen, M., Bishaw, Z., Beshir, A., and De Boef, W. S. Farmers, Seeds, and Varieties: Supporting Informal Seed Supply in Ethiopia, Wageningen International.

Stromberg, P. M., Pascale, U., et al. (2010). Seed Systems and Farmers' Seed Choices: The Case of Maize in the Peruvian Amazon. Human Ecology 38: 539-553.

Teklu, Y., and Hammer, K. (2006). Farmers' Perception and Genetic Erosion of Tetraploid Wheats Landraces in Ethiopia. Genetic Resources and Crop Evolution 53: 1099-1113.

Tesfaye, B. (2008). The Enset (Ensete Ventricosum) Gardens of Sidama: Composition, Structure and Dynamics of a Traditional Poly-Variety System. Genetic Resources and Crop Evolution 55: 1374-1358.

Tunstall, V., Teshome, A., et al. (2001). Distribution, Abundance, and Risk of Loss of Sorghum Landraces in Four Communities in North Shewa and South Welo, Ethiopia. Genetic Resources and Crop Evolution 48: 131-142.

Vadez, V., Reyes-Garcia, V., et al. (2004). Does Integration to the Market Threaten Agricultural Diversity? Panel and CrossSectional Data from a Horticultural-Foraging Society in the Bolivian Amazon. Human Ecology 32(5): 635-646.

Vavilov, N. I., and Chester, K. S. (1951). The Origin, Variation and Breeding of Cultivated Plants. Chronica Botanica 13: 1-366.

vom Brocke, K., Christinck, A., et al. (2003). Farmers' Seed Systems and Management Practices Determine Pearl Millet Genetic Diversity Patterns in Semiarid Regions of India. Crop Science 43: 1680-1689.

Zeven, A. (1998). Landraces: A Review of Definitions and Classifications. Euphytica 104: 127-139. 